\title{
karakteristik Kualitas Pengajar Berdasarkan Faktor Mutu Pelayanan di Jurusan Matematika FMIPA UNSRAT Menggunakan Analisis Biplot
}

\author{
Trisnawaty V. Gobela ${ }^{*}$, Djoni Hatidjaa, Hanny Komaliga \\ aJurusan Matematika, FMIPA, Unsrat, Manado
}

\section{KA TA K UNCI}

Analisis Biplot

Mutu Pelayanan

\section{K E Y W O R S}

Biplot Analysis

Service quality
AVAILABLE ONLINE

31 Januari 2013

\begin{abstract}
A B S TR A K
Tujuan penelitian ini adalah mendeskripsikan faktor penentu mutu pelayanan tenaga pengajar di Jurusan Matematika FMIPA UNSRAT menggunakan analasis biplot. Data yang digunakan adalah data primer yang diperoleh dari 377 peserta 28 matakuliah untuk 18 dosen (DS1, DS2, DS3, DS4, DS5, DS6, DS7, DS8, DS9, DS10, DS11, DS12, DS13, DS14, DS15, DS16, DS17, DS18) pada semester genap TA 2011/2012. Data diambil pada Bulan Mei di Jurusan Matematika FMIPA UNSRAT. Hasilnya menunjukkan bahwa dosen-dosen yang dikategorikan memiliki mutu yang relatif sama unggul terhadap faktor mutu pelayanan adalah DS1, DS2, DS3, DS4, DS6, DS11, dan DS12. Objek-objek yang memiliki mutu yang relatif sama tidak unggul terhadap faktor mutu pelayanan adalah DS5, DS7, DS8, DS9, DS10, DS13, DS14, DS15, DS16, DS17 dan DS18.

A B S T R A C T

The objective of this research was describe service quality factor of lectures at department of mathematics FMIPA UNSRAT using biplot analysis. The data used primary data collected from 377 students of 28 subjects for 18 lecturers (DS1, DS2, DS3, DS4, DS5, DS6, DS7, DS8, DS9, DS10, DS11, DS12, DS13, DS14, DS15, DS16, DS17, DS18) in the second semester 2011/2012. Data were taken in May at department of mathematics FMIPA UNSRAT. The results showed that lecturer who categorized relatively superior quality to service quality factors are DS1, DS2, DS3, DS4, DS6, DS11 and DS12. Then the lecturer who categorized relatively not superior quality to service quality factors are DS5, DS7, DS8, DS9, DS10, DS13, DS14, DS15, DS16, DS17 and DS18.
\end{abstract}

\section{Pendahuluan}

Perguruan tinggi merupakan lembaga pendidikan yang didalamnya terdapat pelayanan jasa pendidikan. Pelayanan adalah kunci keberhasilan dalam berbagai usaha atau kegiatan yang bersifat jasa (Moenir, 2008). Pengukuran kualitas pelayanan dalam hal ini pelayanan pendidikan merupakan elemen penting dalam menyediakan pelayanan yang lebih baik, lebih efisien dan lebih efektif. Dalam perguruan tinggi tenaga pengajar yakni dosen merupakan salah satu bagian yang memberikan pelayanan jasa dan memiliki karakteristik tertentu secara langsung atau tidak langsung dijadikan dasar penilaian oleh mahasiswa. Dengan demikian, pengembangan produk jasa pendidikan dapat dilakukan melalui riset perilaku konsumen jasa pendidikan dan produk jasa pendidikan yang diberikan. Melalui riset ini dapat diperoleh informasi tentang kualitas karakteristik dari suatu produk jasa pendidikan di mata mahasiswa.

Jurusan Matematika Fakultas Matematika dan IImu Pengetahuan Alam Universitas Sam Ratulangi merupakan lembaga pendidikan yang dapat dikatakan sebuah layanan jasa bidang pendidikan. Dalam pemberian jasa pendidikan Jurusan Matematika dituntut tidak hanya memberikan jasa

*Corresponding author: Jurusan Matematika FMIPA UNSRAT, Jl. Kampus Unsrat, Manado, Indonesia 95115; Email address: trisna_gobel@rocketmail.com Published by FMIPA UNSRAT (2013) 
dalam bentuk fisik tetapi juga memberikan pelayanan yang lebih profesional sehingga tercapai kualitas pelayanan yang baik yaitu kualitas pelayanan pendidikan yang didukung oleh tenaga pengajar yang kompeten dalam bidangnya. Mengingat tuntutan dan kebutuhan akan kualitas yang semakin baik, maka penting dilakukan penelitian tentang kualitas pelayanan dosen terhadap proses belajar mengajar disetiap mata kuliah.

Pengukuran kualitas pelayanan dosen dilakukan berdasarkan penilaian mahasiswa terhadap kenyataan yang terjadi selama ini tentang kualitas pelayanan berdasarkan faktor-faktor penentu mutu pelayanan dalam proses belajar mengajar. Semakin banyak peubah yang akan dinilai maka perlu dilihat peubah apa saja yang harus diperhatikan dalam proses belajar mengajar sehingga dapat dijadikan dasar untuk evaluasi diri dan mampu meningkatkan kinerja Jurusan Matematika. Analisis biplot merupakan salah satu bagian dari analisis peubah ganda yang dapat menyajikan secara simultan dalam bentuk gambar dua dimensi antara faktor penentu mutu pelayanan (sebagai peubah) dengan tenaga pengajar (sebagai objek). Posisi yang berdekatan antara objek pada visualisasi biplot menunjukkan adanya persaingan (Kurnia et al, 2002).

Tujuan penelitian ini adalah mengetahui karakteristik kualitas kinerja dosen dalam proses belajar mengajar berdasarkan faktor penentu mutu pelayanan di Jurusan Matematika FMIPA UNSRAT menggunakan analisis Biplot.

\subsection{Studi Literatur}

\subsubsection{Mutu Pelayanan}

Lima faktor yang menentukan mutu pelayanan yaitu Tangible (bukti langsung), Reliability (kehandalan), Responsiveness (daya tanggap), Assurance (jaminan), Empathy (empati) (Ningsih, 2010 dalam Kotler, 2000).

\subsubsection{Analisis Biplot}

Analisis biplot adalah teknik statistika deskriptif yang dapat disajikan secara visual guna menyajikan secara simultan $n$ objek pengamatan dan $p$ peubah dalam ruang bidang datar, sehingga ciri-ciri peubah dan objek pengamatan serta posisi relatif antar objek pengamatan dengan peubah dapat dianalisis (Joliffe, 1986).

Biplot diperkenalkan oleh Gabriel tahun 1971 yang mengembangkan metode biplot sebagai suatu alat analisis data yang dapat meringkas informasi dari suatu matriks data yang besar, dan telah diperbaharui oleh Gower dan Hand pada tahun 1996 (Rencher, 2002). adalah

Empat hal penting yang dapat dilihat pada biplot

1. Hubungan (korelasi) antar peubah, dengan menggunakan biplot peubah akan digambarkan sebagai garis berarah. Dua peubah yang memiliki korelasi positif tinggi akan digambarkan sebagai dua buah garis dengan arah yang sama, atau membentuk sudut yang sempit. Apabila dua peubah yang memiliki korelasi negatif tinggi akan digambarkan dalam bentuk dua garis yang arahnya berlawanan, atau membentuk sudut yang lebar (tumpul). Sedangkan dua buah peubah yang tidak berkorelasi akan digambarkan dalam bentuk dua garis yang mendekati $90^{\circ}$ (siku-siku)

2. Keragaman peubah, informasi ini digunakan untuk melihat apakah ada peubah tertentu yang nilainya hampir sama setiap objek ada yang sama besar dan ada juga yang sangat kecil. Dengan informasi ini, bisa diperkirakan pada peubah mana strategi tertentu harus ditingkatkan, serta sebaliknya. Dalam biplot, peubah dengan keragaman kecil digambarkan dengan vektor yang pendek, sedangkan peubah yang ragamnya besar digambarkan sebagai vektor yang panjang.

3. Kedekatan antar objek, informasi ini bisa dijadikan panduan objek mana yang memiliki kemiripan karakteristik dengan objek tertentu. Dalam biplot, dua objek dengan karakteristik sama akan digambarkan sebagai dua titik yang posisinya berdekatan.

4. Nilai peubah pada suatu objek, informasi ini digunakan untuk melihat keunggulan dari setiap objek. Objek yang terletak searah dengan arah dari suatu peubah dikatakan bahwa pada objek tersebut nilainya diatas rata-rata. Sebaliknya jika objek lain terletak berlawanan dengan arah dari peubah tersebut maka objek tersebut memiliki nilai dekat dengan rata-rata (Mattjik et al, 2004).

Analisis biplot didasarkan pada penguraian nilai singular suatu matriks (Singular Value Decompotion, SVD). Suatu matriks $\boldsymbol{X}_{(\text {(nx) }}$ yang berpangkat $r$ dikoreksi terhadap nilai rataannya, maka matriks tersebut dapat dituliskan menjadi:

$$
X=U L A^{\prime}
$$

dengan matriks $U$ dan $A$ masing-masing berukuran ( $n$ $x r)$ dan $(p x r)$ sehingga $U^{\prime} U=A^{\prime} A=I$. Jika $\lambda_{\mathrm{i}}$ adalah akar ciri dari matriks $X^{\prime} X$, maka $L$ adalah matriks diagonal berukuran $(r \quad x \quad r)$ dengan unsur-unsur diagonal adalah akar kuadrat dari akar ciri $X^{\prime} \mathbf{X}$ sehingga $\sqrt{\lambda_{1}} \geq \sqrt{\lambda_{2}} \geq \cdots \geq \sqrt{\lambda_{r}}$. Unsur-unsur diagonal dari matriks $L$ disebut nilai matriks singular matriks $X$. Kolom-kolom matriks $U$ terdiri dari $r$ vektor ciri dari matriks $X^{\prime} X$. Kolom-kolom matriks $U$ disebut vektor singular kolom matriks $X$ dalam ruang berdimensi $n$. kolom-kolom matriks $A$ terdiri dari $r$ vektor ciri dari matriks $X^{\prime} \mathbf{X}$ yang berpadanan dengan akar ciri $\boldsymbol{\lambda}$. Kolom-kolom matriks $\boldsymbol{A}$ disebut vektor singular baris matriks $\boldsymbol{X}$ dalam ruang berdimensi $\boldsymbol{p}$. Dengan penjabaran persamaan

$$
X=U L A^{\prime}=U L^{\propto} L^{1-\propto} A^{\prime}
$$

dengan pendefinisian $G=U L^{\alpha}$ dan $H=A L^{1-\alpha}$, Untuk 0 $\leq \alpha \leq 1$ persamaan (2) dapat ditulis:

$$
X=G_{(n x r)} H_{(r x p)}^{\prime}
$$

Maka unsur ke-(ij) matriks $X$ dapat ditulis sebagai

$$
X_{i j}=g_{i} h_{j}
$$

dimana $i=1,2,3, \ldots, n$ dan $j=1,2,3, \ldots, p$. 
Jika $\boldsymbol{X}$ berpangkat dua, maka vektor baris $\boldsymbol{g}_{i}$ dan vektor kolom $\boldsymbol{h}_{j}$ dapat digambarkan dalam ruang berdimensi dua. Sedangkan matriks $X$ yang berpangkat lebih dari dua dapat didekati dengan matriks berpangkat dua, sehingga persamaan (4) dapat ditulis menjadi

$$
{ }_{2} X_{i j}=g_{i} * h_{j} \text { * }
$$

dengan masing-masing $g_{i} *$ dan $h_{j} *$ mengandung 2 unsur pertama vektor $g_{i}$ dan $h_{j}$.

Nilai $\alpha$ dapat dinilai sembarang pada interval $0 \leq$ $\alpha \leq 1$ tetapi pengambilan nilai ekstrim $\alpha=0$ dan $\alpha=$ 1 akan berguna untuk mempermudah interpretasi hasil biplot (Wijayanto, 1998 dalam Jolliffe, 1986). Jika $\alpha=0$ maka $G=U$ dan $H=A L$, sehingga

$$
\begin{aligned}
X^{\prime} X & =\left(G H^{\prime}\right)^{\prime}\left(G H^{\prime}\right) \\
& =H G^{\prime} G H^{\prime} \\
& =H U^{\prime} U H^{\prime} \\
& =H H^{\prime}
\end{aligned}
$$

sehingga $X^{\prime} X=H H^{\prime}=(n-1) S$, maka hasil kali $h_{j}{ }^{\prime} h_{k}$ akan sama dengan (n-1) kali peragam $S_{j k}$ dan $h_{j}{ }^{\prime} h_{k}$ menggambarkan peubah ke-k. Oleh sebab itu korelasi peubah ke-j dan peubah ke-k ditunjukkan oleh kosinus antara vektor $\boldsymbol{h}_{j}$ dan $\boldsymbol{h}_{\boldsymbol{k}}$.

Jika $\alpha=1$ maka $\mathrm{G}=\mathrm{UL}$ dan $\mathrm{H}=\mathrm{A}$, sehingga

$$
\begin{aligned}
X^{\prime} X=\left(G H^{\prime}\right)\left(G H^{\prime}\right)^{\prime} \\
=G H^{\prime} H G^{\prime} \\
=G A^{\prime} A G^{\prime} \\
=G G^{\prime}
\end{aligned}
$$

sehingga jarak euclid antara $g_{h}$ dan $g_{i}$ akan sama dengan jarak euclid $\boldsymbol{x}_{\boldsymbol{h}}$ dan $\boldsymbol{x}_{\mathbf{i}}$.

Keakuratan dari biplot dalam menerangkan tingkat keragaman dari matriks data asal dirumuskan sebagai berikut (Everit, 1978)

$$
\rho=\frac{\left(\lambda_{1}+\lambda_{2}\right)}{\sum_{k=1}^{p} \lambda_{k}}
$$

Jika $\rho$ semakin mendekati nilai satu maka biplot yang diperoleh dari matriks pendekatan berpangkat dua akan memberikan penyajian yang semakin baik.

\section{Metode}

\subsection{Data}

Data yang digunakan dalam penelitian adalah data primer menggunakan kuesioner terhadap mahasiswa Jurusan Matematika yang sedang mengikuti matakuliah semester genap TA 2011/2012 yang terdiri dari 28 matakuliah di Jurusan Matematika.

\begin{tabular}{|c|c|c|c|c|c|}
\hline No & $\begin{array}{l}\text { Mata } \\
\text { kuliah }\end{array}$ & No & $\begin{array}{l}\text { Mata } \\
\text { kuliah }\end{array}$ & No & $\begin{array}{l}\text { Mata } \\
\text { kuliah }\end{array}$ \\
\hline 1 & MK1 & 11 & MK11 & 21 & MK21 \\
\hline 2 & MK2 & 12 & MK12 & 22 & MK22 \\
\hline 3 & MK3 & 13 & MK13 & 23 & MK23 \\
\hline 4 & MK4 & 14 & MK14 & 24 & MK24 \\
\hline 5 & MK5 & 15 & MK15 & 25 & MK25 \\
\hline 6 & MK6 & 16 & MK16 & 26 & MK26 \\
\hline 7 & MK7 & 17 & MK17 & 27 & MK27 \\
\hline 8 & MK8 & 18 & MK18 & 28 & MK28 \\
\hline 9 & MK9 & 19 & MK19 & & \\
\hline 10 & MK10 & 20 & MK20 & & \\
\hline
\end{tabular}
Data dikumpulkan pada bulan Mei 2012. Kuesioner tersebar pada 377 peserta 28 matakuliah. Setiap matakuliah terdiri dari 2 dosen/tenaga pengajar untuk itu kuesioner yang disebarkan pada setiap matakuliah mencakup penilaian terhadap 2 dosen tersebut dengan membagi 2 jumlah peserta untuk masing-masing dosen. 28 matakuliah yang termasuk sasaran penilaian disajikan pada tabel berikut:

\begin{tabular}{|c|c|c|c|c|c|c|c|}
\hline 1. & DS1 & 6. & DS6 & 11. & DS11 & 16. & DS16 \\
\hline 2. & DS2 & 7. & DS7 & 12. & DS12 & 17. & DS17 \\
\hline 3. & DS3 & 8. & DS8 & 13. & DS13 & 18. & DS18 \\
\hline 4. & DS4 & 9. & DS9 & 14. & DS14 & & \\
\hline 5. & DS5 & 10. & DS10 & 15. & DS15 & & \\
\hline
\end{tabular}

\section{Tabel 1 - Matakuliah}

\subsection{Variabel Penelitian}

\subsubsection{Objek Penelitian}

Objek penelitian adalah dosen-dosen yang mengajar matakuliah semester genap di Jurusan Matematika FMIPA UNSRAT TA 2011/2012 sebagai berikut:

\section{Tabel 2 - Objek Penelitian}

\subsubsection{Peubah-peubah yang diamati}

Peubah-peubah yang diamati adalah peubah penentu mutu pelayanan yang terdiri dari Kehandalan, Daya Tanggap, Jaminan, Empati, dan Bukti Langsung. berikut:

Peubah-peubah yang diamati adalah sebagai Peubah Kehandalan (kedisiplinan) (X1):

X1a : Kehadiran

X1b : Disiplin Waktu Datang

X1c : Disiplin Waktu Selesai

X1d : Disiplin Waktu Datang Mahasiswa

Peubah Daya Tanggap (X2):

$\begin{aligned} & \mathrm{X} 2 \mathrm{a}: \text { Kesediaan Membantu Mahasiswa } \\ & \mathrm{X} 2 \mathrm{~b}: \text { Pemberian Kesempatan Bertanya } \\ & \mathrm{X} 2 \mathrm{c}: \text { Pemberian Informasi Tentang Silabus } \\ & \mathrm{X} 2 \mathrm{~d}: \begin{array}{l}\text { : Pemberian Informasi tentang Deskripsi } \\ \text { Singkat Materi }\end{array} \\ & \mathrm{X} 2 \mathrm{e}: \begin{array}{l}\text { : Pemberian Informasi tentang Hak dan } \\ \text { Kewajiban Mahasiswa }\end{array} \\ & \mathrm{X} 2 \mathrm{f}: \text { Pemberian Tugas } \\ & \mathrm{X} 2 \mathrm{~g}: \text { Pemberian Kuis }\end{aligned}$


$\mathrm{X} 2 \mathrm{~h}$ : Pemberian Soal Ujian yang Mencakup Seluruh Materi

Peubah Jaminan (Penguasaan materi) (X3):

\begin{tabular}{|c|c|}
\hline X3a & $\begin{array}{l}\text { : Mampu Menjelaskan Materi dengan } \\
\text { Mudah }\end{array}$ \\
\hline $\mathrm{X} 3 \mathrm{~b}$ & : Pemberian Teori Disertai Contoh Praktis \\
\hline X3c & $\begin{array}{l}\text { : Tugas yang Diberi Mampu Membantu } \\
\text { Pemahaman Mahasiswa }\end{array}$ \\
\hline X3d & : Penilaian Hasil Kuis Secara Objektif \\
\hline X3e & $\begin{array}{l}\text { : Kuis yang Diberi Mampu Membantu } \\
\text { Pemahaman Mahasiswa }\end{array}$ \\
\hline X3f & $\begin{array}{l}\text { : Mengajar Sesuai Silabus dan Jadwal } \\
\text { Mingguan }\end{array}$ \\
\hline X3g & : Mengajar Sesuai Keahlian \\
\hline uba & npati (X4): \\
\hline$x 4 a$ & : Pemberian Pujian \\
\hline$x 4 b$ & : Pemberian Teguran \\
\hline eub & ssung \\
\hline$x 5 a$ & : Referensi Yang Digunakan \\
\hline$x 5 b$ & : Komentar Hasil Kuis \\
\hline$X 5 c$ & : Penilaian dan Komentar Tugas \\
\hline$x 5 d$ & : Pemanfaatan Alat Bantu Ajar \\
\hline
\end{tabular}

\subsection{Populasi}

Populasi yang dijadikan objek penelitian adalah dosen-dosen yang mengajar matakuliah di Jurusan Matematika FMIPA UNSRAT pada semester genap TA 2011/2012.

\subsection{Analisis Data}

Metode analisis yang dilakukan dalam penelitian ini ada 2 tahap. Tahapan analisis yang dilakukan adalah sebagai berikut:

1. Data asal dianalisis dengan statistika deskriptif untuk mengetahui gambaran data secara umum menggunakan software Microsoft Excel.

2. Melakukan analisis biplot dengan langkah-langkah sebagai berikut:

- Pemasukan data (matriks data X)

- Penghitungan matriks koragam/peragam S (dengan software Minitab 14

- Pembentukan matriks diagonal yang unsurunsurnya merupakan simpangan baku

- Penghitungan matriks korelasi matriks X (dengan software Minitab 14)

- Standarisasi matriks X (dengan software Minitab 14)

- Penguraian matriks $X$ yang telah distandarisasi dengan SVD

- Penghitungan matriks $\mathrm{H}=\mathrm{AL}$ dan $\mathrm{G}=\mathrm{UL}$

- Plot matriks $\mathrm{G}$ dan H secara tumpang tindih.

Analisis biplot menggunakan makro biplot program Statistical Analysis System versi 9.1.3 (Friendly, 2012).

\section{Hasil dan Pembahasan}

Berdasarkan Gambar 1 dapat dijelaskan bahwa kedekatan antar objek ditunjukkan oleh DS1, DS11, DS3, DS4, DS2, dan DS12 karena jarak keenam objek yang berdekatan. Hal ini menunjukkan bahwa karakteristik keenam objek tersebut relatif sama. Sama halnya dengan DS5, DS16, DS13, DS15, DS17, DS10, DS7, DS14, DS18, DS9 dan DS8.

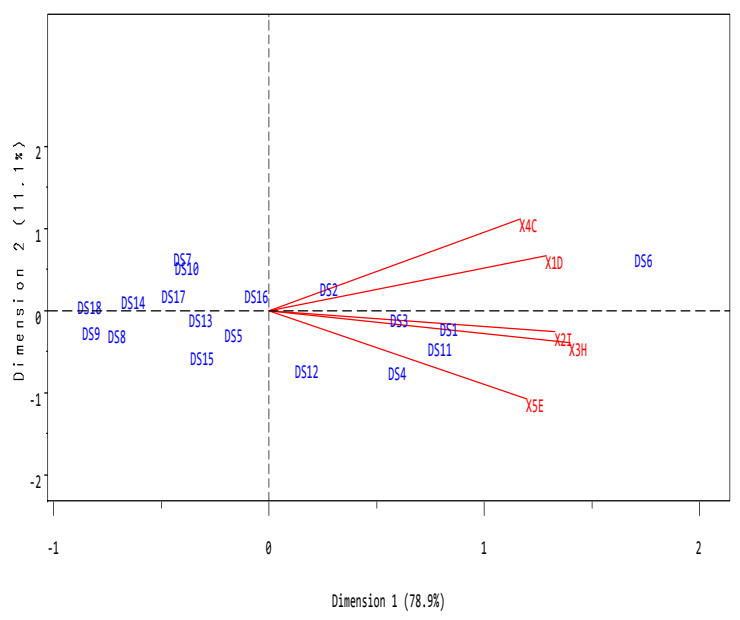

Gambar 1 - Plot antara Peubah (5 faktor penentu mutu pelayanan) dan objek

Keragaman yang diterangkan oleh dimensi 1 sebesar 78,9\% dan dimensi 2 sebesar 11,1\% sehingga total keragamannya sebesar 89,9\%. Keragaman yang terbesar terjadi pada peubah jaminan $(\mathrm{X} 3 \mathrm{H})$ karena memiliki vektor yang paling panjang. Hal ini menunjukkan bahwa dosen-dosen di Jurusan Matematika FMIPA UNSRAT sangat beragam dalam hal faktor jaminan. Keragaman terkecil terjadi pada peubah empati (X4C) karena memiliki vektor yang paling pendek.

Korelasi positif terjadi pada peubah daya tanggap $(\mathrm{X} 2 \mathrm{H})$ dan peubah jaminan $(\mathrm{X} 3 \mathrm{H})$ karena kedua peubah tersebut memiliki arah yang sama dan membentuk sudut lancip. Hal ini berarti bahwa semakin besar daya tanggap yang mencakup keinginan objek untuk membantu para mahasiswa, maka semakin besar jaminan yang dimiliki objek. Selain itu, korelasi positif juga terjadi pada peubah kehandalan (X1F) dan peubah empati (X4C). Hal ini berarti semakin besar kehandalan objek, maka semakin besar empati yang dimiliki objek.

Pada biplot terlihat bahwa DS2 dan DS6 unggul dalam hal kehandalan (kedisiplinan) (X1E) dan empati (X4C) karena vektor dari peubah tersebut searah dengan objek DS2 dan DS6. Selain itu dapat dilihat juga bahwa DS4 dan DS12 unggul dalam hal bukti langsung (X5E). Keunggulan DS1, DS3 dan DS11 yaitu dalam hal jaminan (penguasaan materi) $(\mathrm{X} 3 \mathrm{H})$ dan daya tanggap (X2I).

Gambar 1 juga menunjukkan objek-objek terbagi di kedua sisi namun tidak ada satupun vektor yang 
mengarah ke objek-objek yang berada di kuadran 2 dan kuadran 3. Hal ini berarti objek-objek tersebut memiliki mutu yang relatif sama yakni tidak unggul terhadap 5 faktor penentu mutu pelayanan. Objekobjek tersebut adalah kelompok DS7, DS10, DS18, DS17, DS9, DS15, DS13, DS5, DS14, DS16, dan DS8. Selain itu dapat dilihat beberapa objek berada dikuadran 1 dan kuadran 4 dengan semua vektor peubah yang mengarah ke objek-objek tersebut. Hal ini menunjukkan bahwa objek-objek tersebut memiliki mutu yang relatif sama yakni unggul terhadap 5 faktor penentu mutu pelayanan. Kelompok objek-objek tersebut diantaranya DS6, DS1, DS11, DS3, DS4, DS2 dan DS12.

\section{Kesimpulan}

Berdasarkan hasil dan pembahasan, dapat diambil beberapa kesimpulan yaitu:

a. Objek-objek yang dikategorikan memiliki mutu yang relatif sama yakni unggul terhadap faktorfaktor penentu mutu pelayanan adalah kelompok DS1, DS2, DS3, DS4, DS6, DS11, dan DS12; sedangkan objek-objek yang memiliki mutu yang relatif sama yakni tidak unggul terhadap faktorfaktor penentu mutu pelayanan adalah kelompok DS5, DS7, DS8, DS9, DS10, DS13, DS14, DS15, DS16, DS17 dan DS18.

b. Kelompok DS1, DS3 dan DS11 unggul dalam hal Daya Tanggap (X2I) dan Jaminan (X3H).

c. Kelompok DS2 dan DS6 unggul dalam hal Empati (X4C) dan Kehandalan (X1D).

d. Kelompok DS4 dan DS12 unggul dalam hal Bukti Langsung (X5E).

\section{Daftar Pustaka}

Everit, B. 1978. Graphical Techniques for Multivariate Data. Heinermann Educational Books.

Friendly, M. 1989. Generalized biplot of observations and variable. http://www. datavis.ca/sas/sssg/macros/biplot.sas. [ 29 Juni 2012].

Jolliffe, I.T. 1986 Principal Component Analysis. Springer-Verlag. New York.

Kurnia, A., B. Sartono, dan D. Irvani. 2002. Analisis Biplot Dan Rantai Markov Untuk Menelaah Perilaku Konsumen Majalah Berita Mingguan. Forum Statistika Dan Komputasi. P:18-27.

Mattjik, A.A., M. Sumertajaya, H. Wijayanto, Indahwati, A. Kurnia, B. Sartono. 2004. Modul Teori Pelatihan Analisis Multivariat. Departemen Statistika FMIPA IPB. Bogor.

Moenir, A.S. 2008. Manajemen Pelayanan Umum di Indonesia. Bumi Aksara, Jakarta.

Ningsih, R. 2010. Faktor-faktor Penentu Kepuasan Mahasiswa Terhadap Pelayanan Fakultas sebagai Lembaga Pendidikan (Studi Kasus di FMIPA UNSRAT Manado) [ Skripsi ]. FMIPA UNSRAT. Manado.

Rencher, A.R. 2002. Methods Of Multivariate Analysis Second Edition. John Wiley \& Sons, Inc, New York.

Wijayanto, H, N. Sugihartini, M. Sjamsun, F. Shadry. 1998. Analisis Pengembangan Konsep Produk Menggunakan Metode Biplot. Forum Statistika dan Komputasi Vol.3 No.1, P:1-6. 